\title{
Role of diabetes mellitus on the recurrence rate of hepatocellular carcinomas after radiofrequency ablation in chronic hepatitis $\mathrm{C}$ patients
}

\author{
Abd Allah Ahmed El-Sawy, Mohamed Abd El-Raouf Tawfik
}

Hepatogastroenterology and Endoscopy Unit, Internal Medicine Department, Tanta University Hospital, Tanta 31527, Egypt

\begin{abstract}
Aim: The aim was to assess the impact of hyperglycemia on the recurrence of hepatocellular carcinoma (HCC) as well as evaluate survival after curative ablation by radiofrequency. Methods: This study, which was conducted retrospectively on 107 chronic hepatitis $\mathrm{C}(\mathrm{CHC})$ patients with $159 \mathrm{HCCs}$, was presented to the Hepatology Unit of Internal Medicine Department at Tanta University Hospitals. All lesions were curatively treated by radiofrequency ablation (RFA) and the surveillance of HCC recurrence was evaluated radiologically every 3 months for periods between 6 and 36 months. Of 107 subjects, 70 were males and 37 were females, with mean age $50.4 \pm 9.4$ years. All patients were divided according to their glycemic state into the following three groups: Group I, which included 37 type 2 diabetic patients, with adequate maintenance of blood glucose, has 52 HCCs; Group II, which included 25 type 2 diabetic patients with inadequate maintenance of blood glucose, has 43 HCCs; and Group III, which included 45 euglycemic non-diabetic patients, has 64 HCCs. Results: Our results showed that, there was significant increase in recurrence rate in diabetic patients with inadequate maintenance of blood glucose (Group II) compared to those in Group I and Group III $(P<0.0001)$. Interestingly, there was no significant difference concerning HCC recurrence between diabetic patients with adequate maintenance of blood glucose (Group I) and non-diabetic euglycemic patients (Group III). Our results also identified that, inadequate maintenance of blood glucose in diabetic patients was also a significant predictor of poor survival. Conclusion: Inadequate maintenance of blood glucose in diabetic patients is a significant risk factor for recurrence of $\mathrm{HCC}$ and for poor survival after curative RFA therapy in CHC patients.
\end{abstract}

Key words: Hepatocellular carcinoma; hyperglycemia; radio frequency ablation; recurrence; survival

Address for correspondence:

Dr. Mohamed Abd El-Raouf Tawfik, Hepatogastroenterology and Endoscopy Unit, Internal Medicine Department, Tanta University Hospital, Tanta 31527, Egypt. E-mail: M_atawfik@hotmail.com

Received: 30-12-2014, Accepted: 03-03-2015

\section{INTRODUCTION}

Hepatocellular carcinoma (HCC) is considered as one of the most common cancers worldwide and its incidence has been increasing in many countries. ${ }^{[1]}$ It accounts for $80 \%$ of primary liver cancers, complicating liver cirrhosis in most

\section{Access this article online}

\begin{tabular}{|l|c|}
\hline \multirow{2}{*}{$\begin{array}{l}\text { Website: } \\
\text { http://www.hrjournal.net/ }\end{array}$} & Quick Response Code \\
\hline DOI: & 10.4103/2394-5079.154356
\end{tabular}

cases and the third most common cause of cancer-related deaths. ${ }^{[2]}$

There is considerable geographical variation in the incidence of HCC, which is thought to be related to differences in the prevalence of underlying risk factors, in particular hepatitis B virus (HBV) and hepatitis $\mathrm{C}$ virus (HCV) infections. ${ }^{[3]}$

Hepatocellular carcinoma surgical resection, liver transplantation, and local ablation therapy, such as radio frequency ablation (RFA) therapy, have been considered as efficient curative therapies for HCC. ${ }^{[4]}$ Currently, RFA has gained popularity based on the ease of use, safety, reasonable cost and applicability to minimally invasive techniques. ${ }^{[5]}$ 
RFA therapy is now widely indicated in patients with small $\mathrm{HCC}^{[5]}$ in which the survival rates were similar to surgical resection. ${ }^{[6]}$

Hepatocellular carcinoma has a high rate of recurrence after curative resection or local ablation therapy, reaching approximately $80 \%$ within 5 years. ${ }^{[7-9]}$ The recurrence of HCC and patient survival are associated with the number of HCC nodules and their sizes. ${ }^{[10,11]}$ Hepatic reserve function at the time of HCC therapy is another factor that is associated with the recurrence of HCC and patient survival. ${ }^{[12]}$ Antiviral therapy targeting $\mathrm{HCV}^{[13,14]}$ or $\mathrm{HBV}^{[15]}$ has been shown to decrease HCC recurrence, and improve hepatic reserve function and survival.

There is a strong association between diabetes mellitus and increased cancer risk in liver, the key organ involved in the metabolic derangements typical of diabetes. ${ }^{[16]}$ Metabolic factors, such as obesity and diabetes, are closely linked to the etiology of nonalcoholic steatohepatitis, which is also considered a cause of HCC. ${ }^{[17]}$ If these metabolic factors are related to the recurrence of HCC, therapeutic intervention targeting these factors may lead to prevention of frequent recurrence of HCC and improved patient survival.

The impact of diabetes on the recurrence of HCC, after treatment, has been discussed, but with conflicting results. ${ }^{[18-21]}$ In our study, the possible impacts of hyperglycemia on the recurrence of $\mathrm{HCC}$ in chronic hepatitis $\mathrm{C}(\mathrm{CHC})$ patients after curative RFA were analyzed and we found that inadequate maintenance of blood glucose was related to the high rate of HCC recurrence.

\section{METHODS}

This study was conducted retrospectively on 107 patients with 159 hepatic focal lesions. The patients were curatively treated by RFA therapy from January 2010 to June 2013. There were 70 males and 37 females with mean age $50.4 \pm 9.4$ years.

An informed consent was taken from all participants. All the records were confidential. The results of this research were used only for scientific purpose. Any unexpected risks that appeared during the course of the research were cleared with the participants and the clinical committee on time.

We selected the patients for this study according to the following inclusion criteria: maximum diameter of HCC $\leq 4 \mathrm{~cm}$, number of HCC nodules $\leq 3$, no previous history of treatment of HCC and follow-up observation for at least 6 months and up to 36 months after RFA therapy. The etiological background of liver disease was HCV infection for all patients as other etiology of liver disease were excluded from this study. Exclusion criteria for our study were as following: maximum diameter of $\mathrm{HCC}>4 \mathrm{~cm}$, number of HCC nodules $>3$, previous history of treatment of HCC, follow-up observation for less than 6 months after RFA therapy and cirrhotic patient by other than $\mathrm{CHC}$.

All patients were divided according to glycemic state to the following three groups: Group I included 37 controlled type 2 diabetic patients, with adequate maintenance of blood glucose, with 52 HCC nodules; Group II included 25 uncontrolled type 2 diabetic patients with inadequate maintenance of blood glucose, with 43 HCC nodules; and Group III included 45 euglycemic patients with 64 HCC nodules. The Child-Pugh classification grade was either A $(n=50)$ or B $(n=57)$. The number of HCC nodules was 1 in 61 patients, 2 in 40 patients, and 3 in 6 patients. The maximum diameter of HCC nodules was $3.11 \pm 0.53 \mathrm{~cm}$.

Inadequate maintenance of blood glucose was defined as an average value of casual blood glucose $\geq 200 \mathrm{mg} / \mathrm{dL}$. The level of hemoglobin A1c (HbA1c) was not used in the present study because the lifespan of erythrocytes is shortened due to hypersplenism in patients with chronic hepatitis or cirrhosis, leading to lower $\mathrm{HbA1c}$ levels relative to the blood glucose level. ${ }^{[22]}$ Diagnosis of type 2 diabetes was made according to the American Diabetes Association criteria of a fasting blood glucose level $\geq 126 \mathrm{mg} / \mathrm{dL}$ and/or HbA1c level $\geq 6.5 .{ }^{[23]}$ Obesity was defined as a body mass index $>25 \mathrm{~kg} / \mathrm{m}^{2}$ according to the definition of the Japan Society for the Study of Obesity. ${ }^{[24]}$

After initial treatment of HCC by RFA, the ablated area was confirmed by triphasic computed tomography (CT) or dynamic magnetic resonance imaging (MRI) within 1-week. If the ablated area was not sufficient, then RFA therapy was repeated until the HCC nodule was completely ablated.

Diagnosis of HCC was based on abdominal ultrasonography, triphasic CT, dynamic MRI and alpha-fetoprotein (AFP). Classical HCC was diagnosed for tumors showing vascular enhancement with washout on at least two types of diagnostic imaging. Tumor biopsy was used to diagnose tumors with non-classical imaging findings.

For surveillance of HCC recurrence after curative therapy with RFA, patients were evaluated by abdominal ultrasonography, contrast-enhanced triphasic CT, or contrast-enhanced dynamic MRI every 3 months.

Recurrence of HCC was diagnosed based on reappearance of arterial enhancement in the ablated lesions or new focal 
lesions detected by ultrasonography showing vascular enhancement with washout on triphasic CT or dynamic MRI. If the tumor was not hypervascular, a tumor biopsy was performed to confirm the diagnosis.

\section{Statistical analysis}

All patients' data were tabulated and processed using SPSS 10.0 (SPSS Inc., Chicago, USA). The data were presented by mean and standard deviation and compared using one way analysis of variance test. In addition, the data were presented by frequency and percent and compared using Chi-square test or Fischer's exact test when appropriate. For analysis of survival and recurrence, the time of initial RFA treatment was defined as day 0 . Survival rate was analyzed by the KaplanMeier method and log rank test. Multivariate analysis was performed using a Cox proportional hazard model. In all tests $P$ value was considered significant if $<0.05$.

\section{RESULTS}

The clinical and laboratory characteristics of patients undergoing curative RFA for HCC are summarized in Table 1.

Our results showed that, upon comparison of the three groups, that is, the diabetes with inadequate maintenance of blood glucose group (Group I), the diabetes with adequate maintenance of blood glucose group (Group II), and the euglycemic non-diabetes group (Group III), the recurrence rate was significantly higher in the diabetes with inadequate maintenance of blood glucose group than in the other two groups $(P<0.0001)$ [Figure 1 and Table 2]. On the other hand, there was no significant difference in the HCC recurrence rate between the diabetes patients with adequate

Table 1: The clinical and laboratory criteria for all patients undergoing RFA

\begin{tabular}{lccc}
\hline Variable & $\begin{array}{c}\text { Group I } \\
(n=37) \\
(52 \mathrm{HFL})\end{array}$ & $\begin{array}{c}\text { Group II } \\
(n=25) \\
(43 \mathrm{HFL})\end{array}$ & $\begin{array}{c}\text { Group III } \\
(n=45) \\
(64 \mathrm{HFL})\end{array}$ \\
\hline Age (years) & $50.8 \pm 8.6$ & $53.4 \pm 9.4$ & $50.9 \pm 8.6$ \\
Sex (male/female) & $27 / 10$ & $15 / 10$ & $28 / 17$ \\
ALT (IU/L) & $57.7 \pm 15$ & $59.7 \pm 17.9$ & $61 \pm 18.2$ \\
AST (IU/L) & $50 \pm 7$ & $54.4 \pm 11.4$ & $50.3 \pm 13.4$ \\
Child-Pugh grade (A/B) & $17 / 20$ & $13 / 12$ & $20 / 25$ \\
Casual blood sugar (mg/dL) & $159.9 \pm 7.47$ & $262.0 \pm 44.35$ & $121.3 \pm 25.7$ \\
Maximum diameter of & $3.17 \pm 0.51$ & $3.11 \pm 0.53$ & $3.16 \pm 0.46$ \\
HCC (cm) & & & \\
Number of patient with & $24 / 11 / 2$ & $9 / 14 / 2$ & $28 / 15 / 2$ \\
1/2/3 HCC & & & \\
AFP (ng/mL) & $170.3 \pm 160$ & $169.5 \pm 139.9$ & $182.6 \pm 153.3$ \\
AFP $\geq 200(\mathrm{ng} / \mathrm{mL})$ & $21 / 37$ & $15 / 25$ & $28 / 45$ \\
BMI (kg/m $\left.{ }^{2}\right)$ & $27.9 \pm 0.5$ & $27.2 \pm 2.9$ & $26.5 \pm 3.1$ \\
\hline
\end{tabular}

RFA: radiofrequency ablation; ALT: alanine aminotransferase; AST: aspartate aminotransferase; HCC: hepatocellular carcinoma; AFP: alpha-fetoprotein; BMI: body mass index; HFL: hepatic focal lesion maintenance of blood glucose group and the non-diabetes group $(P=1.0000)$.

With regard to the number of HCC nodules, namely, solitary or multiple, the recurrence rate was significantly higher in patients with multiple HCC nodules in all groups. Within each subgroup of patients with single and multiple HCC nodules, diabetes with inadequate maintenance of blood glucose was significantly associated with recurrence of HCC in comparison to other groups as shown in Figure 1 and Table 2. In terms of the initial level of serum AFP $\geq 200 \mathrm{ng} / \mathrm{mL}$, the recurrence rate was significantly higher in patients with AFP $\geq 200 \mathrm{ng} / \mathrm{mL}$ in all groups. Within each subgroup of patients with AFP $\geq 200 \mathrm{ng} / \mathrm{mL}$ and $<200 \mathrm{ng} / \mathrm{mL}$, diabetes with inadequate maintenance of blood glucose was associated with a higher rate of recurrence in comparison to other groups as shown in Figure 1 and Table 2. On the other hand, obesity was not significantly associated with HCC recurrence in all groups.

As shown in Figure 2, the survival rate was significantly lower in diabetic patients with inadequate maintenance of blood glucose (solid line) than in diabetic patients with adequate maintenance of blood glucose (blood glucose $<200 \mathrm{mg} / \mathrm{dL}$, broken line) or non-diabetic patients (dotted line) $(P=0.0060)$. There was no significant difference in survival rate between diabetic patients with adequate maintenance of blood glucose and non-diabetic patients.

\section{DISCUSSION}

The effect of metabolic factors, such as hyperglycemia, diabetes, and obesity, on the recurrence of HCC after curative RFA therapy was analyzed retrospectively. Our results identified that inadequate maintenance of blood glucose in diabetic patients was a significant and independent risk factor for early recurrence of HCC, whereas obesity and

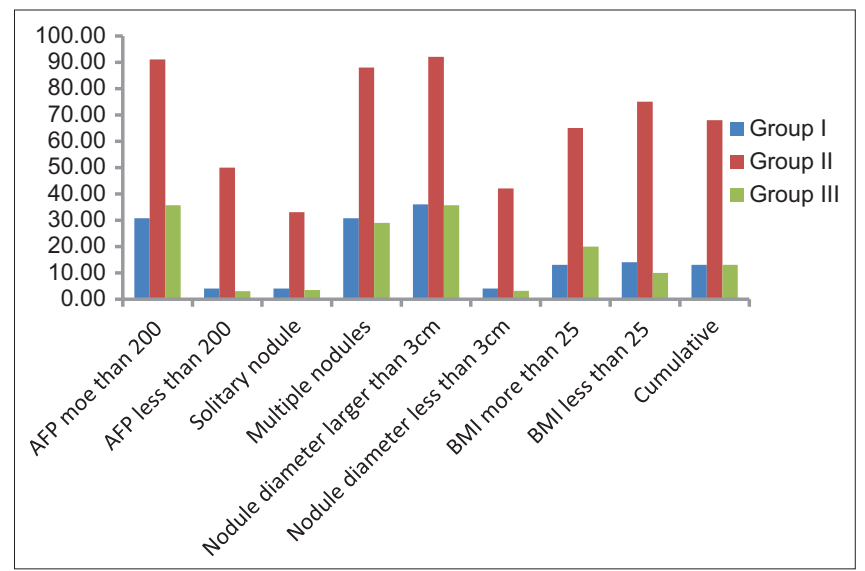

Figure 1: The recurrence of all studied patients as regard all risk factors after radiofrequency ablation (AFP: alpha-fetoprotein; BMI: body mass index) 
Table 2: The recurrence of all studied patients as regard all risk factors after RFA

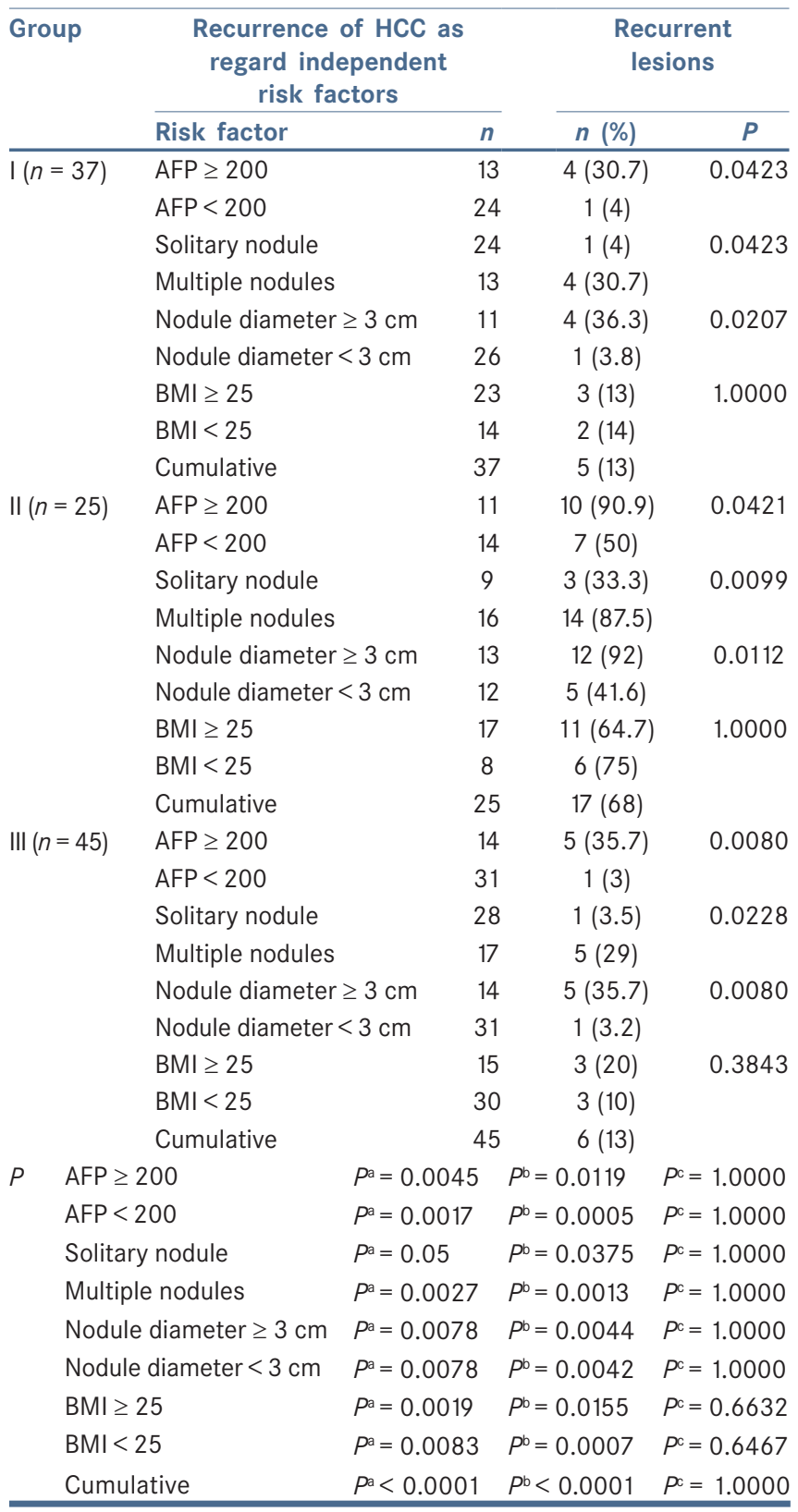

a $P$ : $P$ value between Group I and II; ${ }^{\mathrm{b}} P$ : $P$ value between Group II and III; ' $P$ : $P$ value between Group I and III. Group I: inadequate maintenance of blood glucose; Group II: adequate maintenance of blood glucose; Group III: non-diabetic euglycemic. HCC: hepatocellular carcinoma; AFP: alpha-fetoprotein; BMI: body mass index; RFA: radiofrequency ablation

diabetes with adequate maintenance of blood glucose were not. This was based on the results that showed that diabetic patients with inadequate maintenance of blood glucose had a higher rate of HCC recurrence compared with diabetic patients with adequate maintenance of blood glucose and non-diabetic patients. In other words, even in patients with diabetes, if the blood glucose was adequately maintained, the HCC recurrence rate did not differ significantly compared with those in non-diabetic patients. These results indicate the

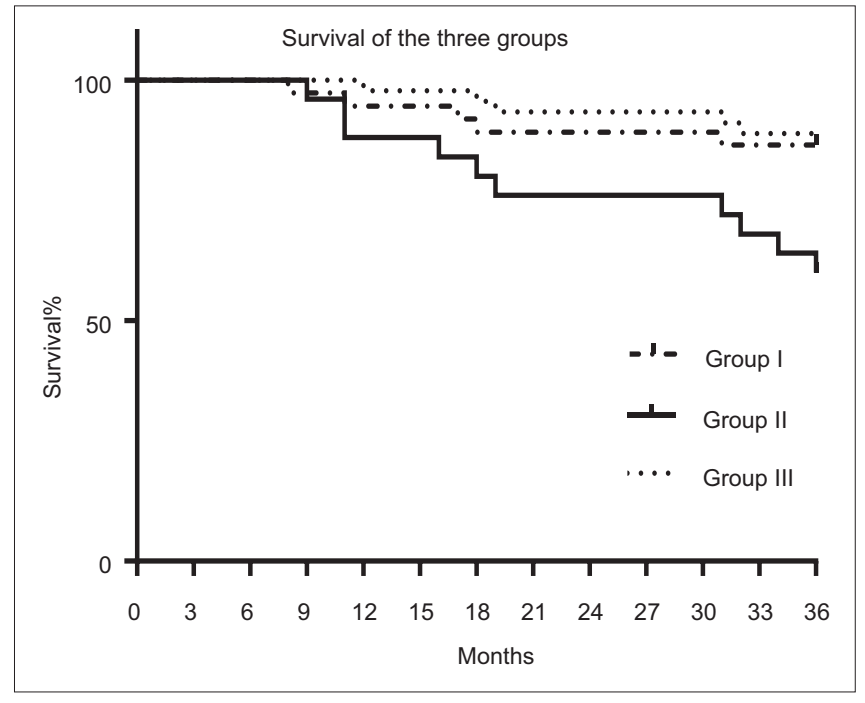

Figure 2: Survival rate in all groups

possibility that adequate management of hyperglycemia may lead to a reduction in the risk of HCC recurrence.

These results have been confirmed by several authors. ${ }^{[25-29]}$ There may be several mechanisms involved in the relationship between hyperglycemia and HCC recurrence. Hyperglycemia promotes cancer cell proliferation in pancreatic cancer cells and breast cancer cells through accelerated cell cycle progression or through the production of reactive oxygen species, leading to activation of protein kinase $C$ and increased DNA synthesis in cancer cells. ${ }^{\text {[0-33] }}$

Takahashi et al. ${ }^{[34]}$ proved that post-challenge hyperglycemia is a significant risk factor for the development of HCC in patients with $\mathrm{CHC}$ while hyperglycemia at fasting was not. A possible reason for this result may be that patients with post-challenge hyperglycemia may have higher fluctuations in daily glucose levels that lead to oxidative stress. ${ }^{[34]}$ This is because it was reported that acute fluctuations in blood glucose levels cause greater oxidative stress than sustained chronic hyperglycemia. ${ }^{[3]}$ Taken together, a possible mechanism for the relationship between higher level of casual blood glucose and development of HCC in the present study may be that daily fluctuations in serum glucose levels caused greater oxidative stress. Alternatively, hyper-insulinemia or increased level of insulin-like growth factor, which are caused by hyperglycemia, may be related to carcinogenesis. ${ }^{[36]}$

The results of our study identified that, the survival rate was significantly lower in diabetic patients with inadequate maintenance of blood glucose than in diabetic patients with adequate maintenance of blood glucose or non-diabetic patients. There was no significant difference in survival rate between diabetic patients with adequate maintenance of blood glucose and non-diabetic patients. 
These results were confirmed by Hosokawa et al. ${ }^{[25]}$ who suggested that glycemic control in diabetic patients, more so than diabetes itself, plays a role in the survival. The mechanism by which glycemic control and survival are related is unknown, but frequent recurrence of HCC in hyperglycemic patients and the accumulation of damage in liver function because of repeated treatment intervention for HCC may lead to worsening survival. Diabetes accelerates liver fibrosis and inflammation with increased inflammatory markers and cytokines resulting in severe liver failure and poor cancer prognosis. ${ }^{[25]}$

In conclusion, inadequate maintenance of blood glucose in diabetic patients is a significant risk factor for recurrence of HCC and for poor survival after curative RFA therapy in CHC patients.

\section{REFERENCES}

1. Parkin DM, Bray F, Ferlay J, Pisani P. Global cancer statistics, 2002. CA Cancer J Clin 2005;55:74-108.

2. Bosch FX, Ribes J, Díaz M, Cléries R. Primary liver cancer: worldwide incidence and trends. Gastroenterology 2004;127:S5-16.

3. Gomaa AI, Khan SA, Toledano MB, Waked I, Taylor-Robinson SD. Hepatocellular carcinoma: epidemiology, risk factors and pathogenesis. World J Gastroenterol 2008;14:4300-8.

4. Arii S, Sata M, Sakamoto M, Shimada M, Kumada T, Shiina S, Yamashita T, Kokudo N, Tanaka M, Takayama T, Kudo M. Management of hepatocellular carcinoma: Report of Consensus Meeting in the 45th Annual Meeting of the Japan Society of Hepatology (2009). Hepatol Res 2010;40:667-85.

5. Minami Y, Kudo M. Radiofrequency ablation of hepatocellular carcinoma: current status. World J Radiol 2010;2:417-24.

6. Chen MS, Li JQ, Zheng Y, Guo RP, Liang HH, Zhang YQ, Lin XJ, Lau WY. A prospective randomized trial comparing percutaneous local ablative therapy and partial hepatectomy for small hepatocellular carcinoma. Ann Surg 2006;243:321-8.

7. Tateishi R, Shiina S, Teratani T, Obi S, Sato S, Koike Y, Fujishima T, Yoshida H, Kawabe T, Omata M. Percutaneous radiofrequency ablation for hepatocellular carcinoma. An analysis of 1000 cases. Cancer 2005;103:1201-9.

8. Izumi N, Asahina Y, Noguchi O, Uchihara M, Kanazawa N, Itakura J, Himeno Y, Miyake S, Sakai T, Enomoto N. Risk factors for distant recurrence of hepatocellular carcinoma in the liver after complete coagulation by microwave or radiofrequency ablation. Cancer 2001;91:949-56.

9. Curley SA, Izzo F, Ellis LM, Nicolas Vauthey J, Vallone P. Radiofrequency ablation of hepatocellular cancer in 110 patients with cirrhosis. Ann Surg 2000;232:381-91.

10. Poon RT, Fan ST, Lo CM, Liu CL, Wong J. Intrahepatic recurrence after curative resection of hepatocellular carcinoma: long-term results of treatment and prognostic factors. Ann Surg 1999;229:216-22.

11. Tung-Ping Poon R, Fan ST, Wong J. Risk factors, prevention, and management of postoperative recurrence after resection of hepatocellular carcinoma. Ann Surg 2000;232:10-24.

12. Fuke H, Sugimoto K, Shiraki K, Tanaka J, Beppu T, Yoneda K, Yamamoto N, Ito K, Takaki H, Nakatsuka A, Yamakado K, Takeda K, Takei Y. Predictive factors for distant recurrence of HCV-related hepatocellular carcinoma after radiofrequency ablation combined with chemoembolization. Aliment Pharmacol Ther 2008;27:1253-60.

13. Hagihara H, Nouso K, Kobayashi Y, Iwasaki Y, Nakamura S, Kuwaki K, Toshimori J, Miyatake H, Ohnishi H, Shiraha H, Yamamoto K. Effect of pegylated interferon therapy on intrahepatic recurrence after curative treatment of hepatitis C virus-related hepatocellular carcinoma. Int J Clin Oncol 2011;16:210-20.

14. Miyake Y, Takaki A, Iwasaki Y, Yamamoto K. Meta-analysis: interferon-alpha prevents the recurrence after curative treatment of hepatitis C virus-related hepatocellular carcinoma. J Viral Hepat 2010;17:287-92.

15. Wong JS, Wong GL, Tsoi KK, Wong VW, Cheung SY, Chong CN, Wong J, Lee KF, Lai PB, Chan HL. Meta-analysis: the efficacy of anti-viral therapy in prevention of recurrence after curative treatment of chronic hepatitis B-related hepatocellular carcinoma. Aliment Pharmacol Ther 2011;33:1104-12.

16. Inoue M, Iwasaki M, Otani T, Sasazuki S, Noda M, Tsugane S. Diabetes mellitus and the risk of cancer: results from a large-scale population-based cohort study in Japan. Arch Intern Med 2006;166:1871-7.

17. Bugianesi E, Leone N, Vanni E, Marchesini G, Brunello F, Carucci P, Musso A, De Paolis P, Capussotti L, Salizzoni M, Rizzetto M. Expanding the natural history of nonalcoholic steatohepatitis: from cryptogenic cirrhosis to hepatocellular carcinoma. Gastroenterology 2002;123:134-40.

18. Toyoda H, Kumada T, Nakano S, Takeda I, Sugiyama K, Kiriyama S, Tanikawa M, Sone Y, Hisanaga Y. Impact of diabetes mellitus on the prognosis of patients with hepatocellular carcinoma. Cancer 2001;91:957-63.

19. Huo TI, Wu JC, Lui WY, Huang YH, Lee PC, Chiang JH, Chang FY, Lee SD. Differential mechanism and prognostic impact of diabetes mellitus on patients with hepatocellular carcinoma undergoing surgical and nonsurgical treatment. Am J Gastroenterol 2004;99:1479-87.

20. Komura T, Mizukoshi E, Kita Y, Sakurai M, Takata Y, Arai K, Yamashita T, Ohta T, Shimizu K, Nakamoto Y, Honda M, Takamura T, Kaneko S. Impact of diabetes on recurrence of hepatocellular carcinoma after surgical treatment in patients with viral hepatitis. Am J Gastroenterol 2007;102:1939-46.

21. Chen WT, Macatula TC, Lin CC, Lin CJ, Lin SM. Diabetes may not affect outcomes in hepatocellular carcinoma after radio-frequency ablation. Hepatogastroenterology 2011;58:551-7.

22. Aizawa N, Enomoto H, Imanishi H, Saito M, Iwata Y, Tanaka H, Ikeda N, Sakai Y, Takashima T, Iwai T, Moriwaki E, Shimomura S, Iijima H, Nakamura H, Nishiguchi S. Elevation of the glycated albumin to glycated hemoglobin ratio during the progression of hepatitis $\mathrm{C}$ virus related liver fibrosis. World J Hepatol 2012;4:11-7.

23. American Diabetes Association. Diagnosis and classification of diabetes mellitus. Diabetes Care 2010;31:S62-9.

24. Youkou A, Hasegawa T, Suzuki K, Koya T, Sakagami T, Toyabe S, Arakawa M, Gejyo F, Narita I, Suzuki E. Influence of obesity on control in asthmatic Japanese patients defined by the Japanese definition of obesity. Intern Med 2011;50:1911-6.

25. Hosokawa T, Kurosaki M, Tsuchiya K, Matsuda S, Muraoka M, Suzuki Y, Tamaki N, Yasui Y, Nakata T, Nishimura T, Suzuki S, Ueda K, Nakanishi H, Itakura J, Takahashi Y, Izumi N. Hyperglycemia is a significant prognostic factor of hepatocellular carcinoma after curative therapy. World J Gastroenterol 2013;19:249-57.

26. Davila JA, Morgan RO, Shaib Y, McGlynn KA, El-Serag HB. Diabetes increases the risk of hepatocellular carcinoma in the United States: a population based case control study. Gut 2005;54:533-9.

27. Lai MS, Hsieh MS, Chiu YH, Chen TH. Type 2 diabetes and hepatocellular carcinoma: a cohort study in high prevalence area of hepatitis virus infection. Hepatology 2006;43:1295-302.

28. El-Serag HB, Hampel H, Javadi F. The association between diabetes and hepatocellular carcinoma: a systematic review of epidemiologic evidence. Clin Gastroenterol Hepatol 2006;4:369-80. 
29. Hassan MM, Hwang LY, Hatten CJ, Swaim M, Li D, Abbruzzese JL, Beasley P, Patt YZ. Risk factors for hepatocellular carcinoma: synergism of alcohol with viral hepatitis and diabetes mellitus. Hepatology 2002;36:1206-13

30. Liu H, Ma Q, Li J. High glucose promotes cell proliferation and enhances GDNF and RET expression in pancreatic cancer cells. Mol Cell Biochem 2011;347:95-101.

31. Okumura M, Yamamoto M, Sakuma H, Kojima T, Maruyama T, Jamali M, Cooper DR, Yasuda K. Leptin and high glucose stimulate cell proliferation in MCF-7 human breast cancer cells: reciprocal involvement of PKC-alpha and PPAR expression. Biochim Biophys Acta 2002;1592:107-16.

32. Yamamoto M, Patel NA, Taggart J, Sridhar R, Cooper DR. A shift from normal to high glucose levels stimulates cell proliferation in drug sensitive MCF-7 human breast cancer cells but not in multidrug resistant MCF-7/ADR cells which overproduce PKC-betaII. Int J Cancer 1999;83:98-106.

33. Nishikawa T, Edelstein D, Du XL, Yamagishi S, Matsumura T, Kaneda Y, Yorek MA, Beebe D, Oates PJ, Hammes HP, Giardino I, Brownlee M. Normalizing mitochondrial superoxide production blocks three pathways of hyperglycaemic damage. Nature 2000;404:787-90.
34. Takahashi H, Mizuta T, Eguchi Y, Kawaguchi Y, Kuwashiro T, Oeda S, Isoda $\mathrm{H}$, Oza N, Iwane S, Izumi K, Anzai K, Ozaki I, Fujimoto K. Post-challenge hyperglycemia is a significant risk factor for the development of hepatocellular carcinoma in patients with chronic hepatitis C. J Gastroenterol 2011;46:790-8.

35. Monnier L, Mas E, Ginet C, Michel F, Villon L, Cristol JP, Colette C. Activation of oxidative stress by acute glucose fluctuations compared with sustained chronic hyperglycemia in patients with type 2 diabetes. JAMA 2006;295:1681-7.

36. Fisher WE, Boros LG, Schirmer WJ. Insulin promotes pancreatic cancer: evidence for endocrine influence on exocrine pancreatic tumors. $J$ Surg Res 1996;63:310-3.

How to cite this article: El-Sawy AA, Tawfik MA. Role of diabetes mellitus on the recurrence rate of hepatocellular carcinomas after radiofrequency ablation in chronic hepatitis C patients. Hepatoma Res 2015;1:24-9.

Source of Support: Nil. Conflict of Interest: None declared. 